\title{
Representation of Human Intent in Product Models
}

\author{
László Horváth \\ Department of Manufacturing Engineering, Bánki Donát \\ Polytechnic \\ Népszínház u. 8., Budapest H-1081, Hungary, phone: (36-1)-313- \\ 8657,fax: (36-1)-333-6761, e-mail: lhorvath@zeus.banki.hu \\ Imre J. Rudas \\ Department of Information Technology, Bánki Donát Polytechnic \\ Népszínház u. 8, Budapest H-1081 Hungary, phone: (36-1)-333- \\ 4513, fax: (36-1)-333-9183, e-mail: rudas@zeus.banki.hu
}

\begin{abstract}
Engineering design and planning have become globalized activities in the industry. As a result, transferring product models between CAD/CAM systems is emphasized in these days. An engineer needs information about intention of the engineer who has created the model at a remote workstation. Present day geometric and form feature models of mechanical parts offer only restricted description of human intent. There are efforts to improve this characteristic of shape models. Authors propose in this paper a methodology for attaching information and knowledge to geometric and form feature models for improving communication between product designer and production engineer. The paper is organized as follows. First, product modeling and production planning procedures are analyzed for the needs for design intent information to be transferred between product designers and manufacturing engineers. Next, product
\end{abstract}

The original version of this chapter was revised: The copyright line was incorrect. This has been corrected. The Erratum to this chapter is available at DOI: 10.1007/978-0-387-35390-6_58 
models and their information description capabilities are explained and a concept for description of designer intent and experience in these models is presented. Following this, representation and processing of human intent are described. Finally characteristics and advantages of communication between engineers using the extended models are concluded.

\section{Keywords}

Product modeling, modeling of design intent, data exchange, communication amongst engineers

\section{INTRODUCTION}

Sophisticated modeling methods make it possible to create computer representation of objects that are designed by engineers. With the globalization of the industry, more and more models are transferred between CAD/CAM systems using their own or neutral data formats. In the course of their application, models are processed by computer programs that rely upon different principles. In the recent years collaborative engineering methods were developed to help engineers at their group work (Cruinkshank, D., 1996). This is the way that leads to advanced software environments for simultaneous engineering processes. Multimedia, videoconferencing and advanced $3 \mathrm{D}$ computer graphics are utilized. Engineers are in interactive dialog with modeling procedures at the application of the model and need information and knowledge about intention of the engineers who have created the model. Moreover, information exchange about application and allowed modification of the model improves the cooperation between the engineers. Implementation of knowledge based principles in these systems will have an important emphasis in the future. Researchers are keenly investigate design intent (Haasbroek, L. J., 1993).

Authors investigated the above outlined problem complex and proposed a methodology for attaching intent and application information as well as knowledge to geometric and form feature models of mechanical parts (László Horváth and Imre J. Rudas, 1997). This methodology is shown in this paper. The aim is to establish an improved communication between product designer and production engineer. Following the methodology, special procedures can be developed for processing information and knowledge on designer intent. CAD/CAM software packages offer development tools that are appropriate for this purpose. Design intent is basically application oriented, however there are also generally applicable intent definitions. Authors analyzed some of the newly developed real world CAD/CAM systems with open architecture (Schild, P. J. and Klemm, W. and Walz and G. J., Ruess, H. J., 1995). In their earlier papers, they described experiences on human-computer processes and 
distortion of design intent in an engineering design and planning environment (László Horváth and Imre J. Rudas, 1994, 1995).

The paper is organized as follows. First, product modeling and production planning procedures are analyzed from the point of view of need for design intent information to be transferred between product designers and manufacturing engineers. Next, product models and their information description capabilities are explained and a concept for description of designer intent and experience in these models is presented. Following this, representation and processing of intent are described. Finally characteristics and advantages of communication between engineers using the extended models are concluded.
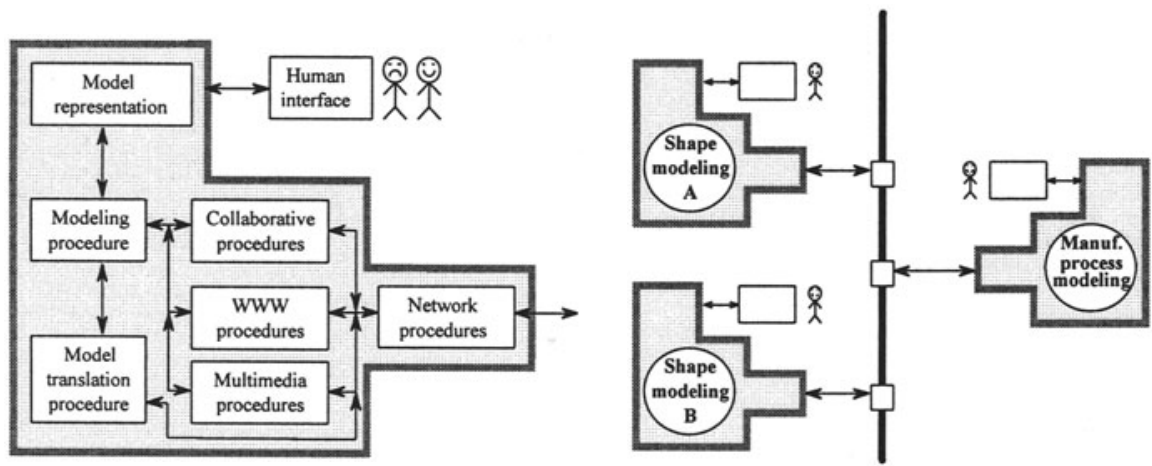

Figure 1. Modeling activities at workstations in a computer network

\section{COMMUNICATION OF MODELING PROCEDURES AND ENGINEERS}

Shape modeling and manufacturing process modeling are key technics in design and production engineering of mechanical parts. Product designer creates shape model concept that includes shape, dimension tolerance and material information. Production engineer evaluates this model for manufacturability and economical production and suggests modifications in this early stage of product development. Then the design is detailed and the manufacturing process is planned. These activities make the use of sophisticated shape and manufacturing process models, respectively (László Horváth and Imre J. Rudas, 1996).

Shape models are pure geometric ones or involve form features. Form feature is an application oriented shape aspect. Model data are shared amongst members of a group 
of engineers using collaborative procedures (Figure 1.). Engineers annotate the model. Using the received multimedia annotations, design engineer creates an improved shape model of the part and sends it to other engineers for additional design, analysis and manufacturing planning. Model data structures are created and used by interactive computer procedures and model data sets are exchanged between the CAD/CAM systems that create or apply models. Different model data bases of various CAD/CAM systems make it necessary the translation of model data.

Consequently, the entire engineering procedure involves a communication between computer procedures and an another communication between engineers, simultaneously. Engineers communicate directly and indirectly. The latter is done through computer procedures that carry intent of their developers (Figure 2.). Build in knowledge of model creation procedures is communicated with engineers who use these procedures. In this paper, the aspect of intention exchange between engineers is analyzed.

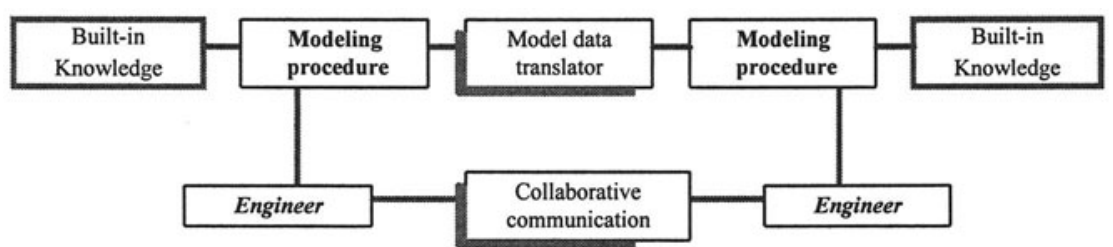

Figure 2. Data exchange and collaborative communication in an engineering environment

Data exchange between modeling procedures means exchange of parameters of model entities (e. g. IGES) or exchange of a product model. For exchange product models, the Integrated Product Information Model of the STEP (Standard for Exchange of Product Model Data, ISO 10303) is being developed. Integrated product models in advanced $\mathrm{CAD} / \mathrm{CAM}$ systems involve some information on design intent. Authors wish to join to recent efforts of researchers for developing methods of handling of design intent information and knowledge in these models.

\section{DESCRIPTION CAPABILITIES OF GEOMETRIC AND FORM FEATURE MODELS}

Usual information description capability of shape models is confined to modeled objects and their attributes. Moreover, there are user defined parameters and user may define relation between parameters of entities. If description of design intent information and knowledge is needed, open architecture and product model description languages make it possible to attach these descriptions to models. The approach of the 
authors is to define design intent model entities. A description that involves experience of the designer and useful information for the application of the model is involved too. In this paper three basic partial models of the product model are considered (Figure 3.). These represent the shape model and one of its most important applications.

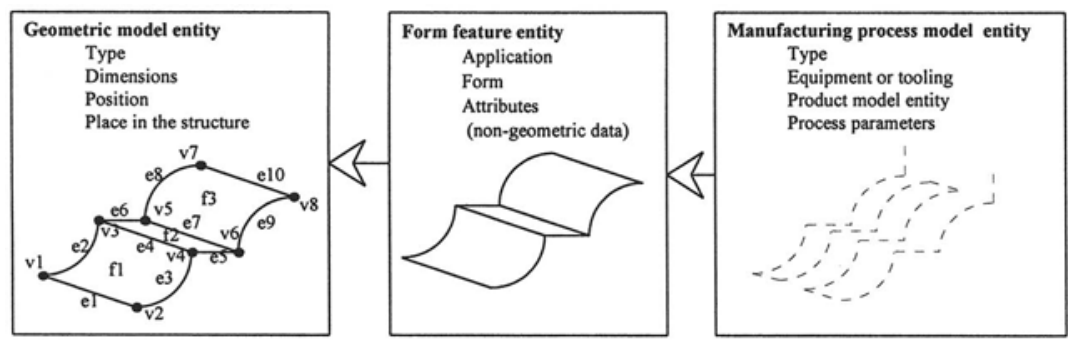

Figure 3. Shape related partial models of the product model

Basically, there are intent definitions regarding the design and the application of the shape model (Figure 4.). Status of the intent carries information on the origin of the intent information or knowledge. There are alternatives that can be taken account at the application of the model without notice. There is often an allowable range of some parameters within which the model can be modified by the production engineer without any permission from the designer. This can be done by the production engineer because shape modeling tools are available for her or him. Dramatic shortening of the product development cycle can be realized in this manner. In communication of design engineers a simple video can show a shape that the designer likes and is insisted on. An intent definition for application of the part model among others may involve the preferred type of application, strategy and process parameters.

\begin{tabular}{|c|c|}
\hline $\begin{array}{l}\text { Intent regarding the design } \\
\text { (multiple intent may be defined) } \\
\text { Why that type } \\
\text { Possible alternatives } \\
\text { Is compatible with ... } \\
\text { Is not compatible with ... } \\
\text { Allowable range of dimensions } \\
\text { Fixed characteristics } \\
\text { Environment } \\
\text { Rules } \\
\text { Equations } \\
\text { Pictured } \\
\text { Voice } \\
\text { Motion pictured }\end{array}$ & $\begin{array}{l}\text { Status of the intent } \\
\text { (multiple status } \\
\text { may be defined) } \\
\text { Standard } \\
\text { Responsibilty } \\
\text { Custom } \\
\text { Customary } \\
\text { Experience } \\
\text { Explained } \\
\text { Asked } \\
\text { Wished } \\
\text { Opinion } \\
\text { Maybe }\end{array}$ \\
\hline $\begin{array}{l}\text { Intent regarding the application } \\
\text { (multiple applications and intent } \\
\text { may be defined) }\end{array}$ & $\begin{array}{c}\text { Modeling at } \\
\text { product } \\
\text { development }\end{array}$ \\
\hline $\begin{array}{l}\text { Application type } \\
\text { Constraints for process parameters } \\
\text { Intended strategy } \\
\text { Counter-proposal }\end{array}$ & Application \\
\hline
\end{tabular}

Figure 4. Intents and their status 
The status of the intent may vary from the standard to maybe. The standard intent is based on standard. If the status of an intent is responsibility, it is based on decision of the person who is responsible for the design. There are weak intents as opinion and maybe. Figure 4 shows examples for intents and their status. In a given collaborative design and planning environment a specific choice can be defined according to the nature of the design task and the organization of design and planning.

\section{REPRESENTATION AND PROCESSING OF INTENT}

Intent information and knowledge are handled as auxiliary model information in the proposed model. User defined entities can be attached to the model or the data structures can be stored in a separate data file. If the model is written using some model description language such as Express in STEP, the intent definition may be involved in the model.

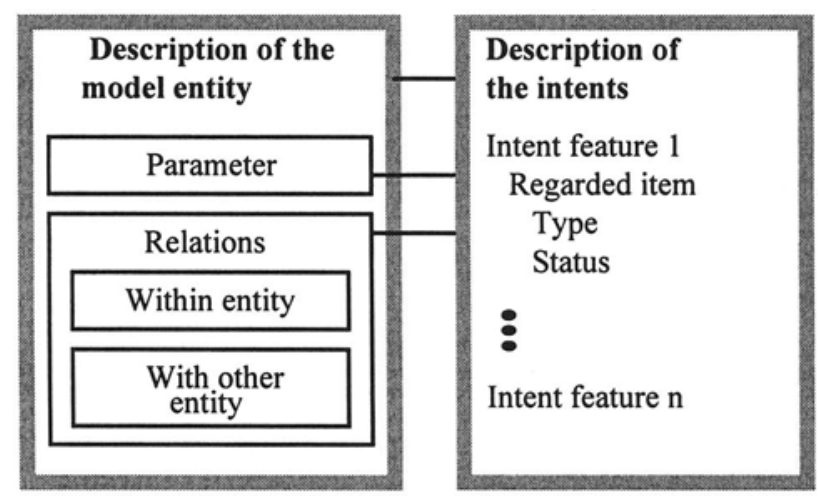

Figure 5. Model entities and intent descriptions

Intent can be attached to a model entity or to a group of entities as intent feature. It may be related to an entity, to an entity parameter, to a relation within the entity or to a relation between entities (Figure 5.). Description of the intents for a model entity involves all the intents defined for that entity.

A typical application of geometric model entities is generation of numerical control cycles for machining. Some modification of the shape to achieve optimal tool path can be allowed. As an example, a radius can be defined according to the optimal tool diameter within a range of its allowed values. At certain parts a given strategy of machining must be applied to achieve the preferred pattern of tool paths. 
Process of attaching intent definition to model entities can be summarized as follows. Model entity is generated by the appropriate modeling procedure. An intent can be defined by a human, by a model creation procedure or by a knowledge processing procedure (Figure 6.). All of these were originally human intents. Humans can program intent definition procedures into modeling procedures and can define knowledge for automatic generation of intents. Learning procedures collect knowledge for automatic definition of intents. This knowledge can also be defined by a local human or it may come from some outside source.

Describing of an intention in an exchangeable model inherently means its saving for all future applications and developments of the model. Intention is distorted if its description is not accurate or correct. Moreover, intention may be distorted by misunderstanding or conversion. Subjective opinions and suggestions are hard to describe as a simple information in the practice. Among others, this is why knowledge as representation of an intent has of great importance. Rules and decision trees as simple knowledge carriers can be referred by an intention description. As in all knowledge-based, systems explanation of different forms can assist the utilization of the knowledge.

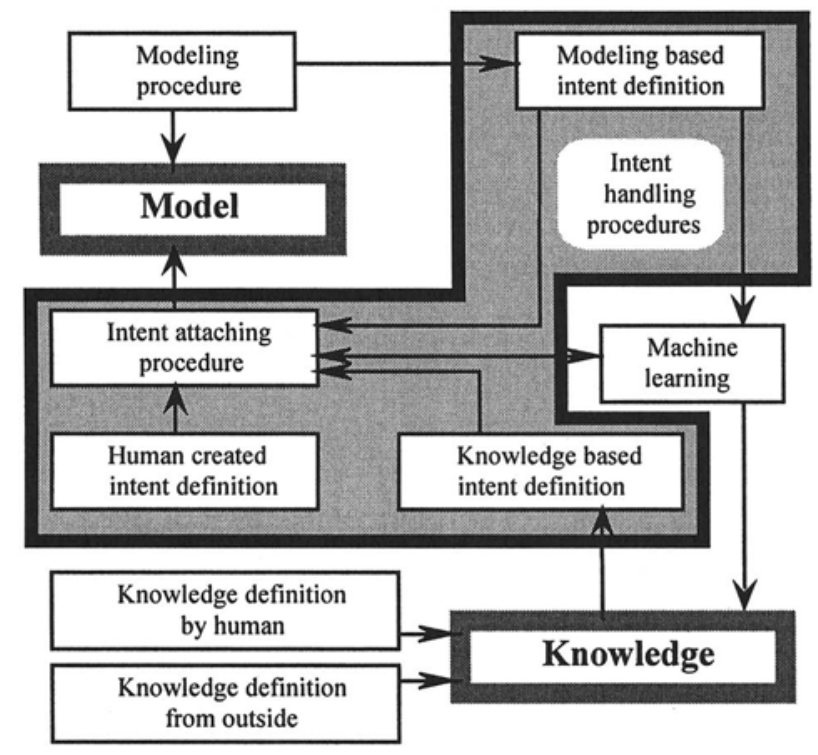

Figure 6. Intent creation procedure 


\section{COMMUNICATION AMONGST ENGINEERS}

As usual, a group of engineers is working on a project. Engineers can communicate through definition and understanding of design intent descriptions that are attached to model entities.

An important aspect is modeling of the communication procedure amongst humans. There are humans of different status. Each communication serves a defined purpose (Figure 7.). Sometimes important parameters of a model entity are defined by a sequence of communications amongst engineers (Figure 7.). Status of the human defines a position or a role in the design and planning environment. The range of aims of communication starts with giving information and ends with command. Lists may be defined according to the area of the application. An example can be seen on Figure 7. Status together with aim determines the strength of the communication. Best cooperation of engineers is essential for the best result.

\begin{tabular}{|c|c|c|c|}
\hline Status of the human & Aims of communication & \multicolumn{2}{|c|}{$\begin{array}{c}\text { History of the communication } \\
\text { for an item }\end{array}$} \\
\hline Responsible for & Giving information & human & \\
\hline Decides on & Asking & Makes proposal & For discuss \\
\hline Applier & Worrying about & Decides on & Worrying about \\
\hline Approver & For discuss & Makes proposal & For discuss \\
\hline Makes proposal & Suggested & Makes proposal & For discuss \\
\hline Customer & Proved & Decides on & Decision \\
\hline Authority & To be improved & Customer & Requirement \\
\hline Analyzer & Disputed & Responsible for & For approval \\
\hline & & Authority & Approval \\
\hline Approval & For approval & & \\
\hline Decision & Requirement & & \\
\hline Command & Compulsory & & \\
\hline
\end{tabular}

Figure 7. Communication between engineers

History of a communication (Figure 7) can be recorded similarly to the history of the model creation. A sequence of communications is recorded for a given item. The item may be anything that demands discussion and decision in the design and planning process. 
Intent description and collaborative communication enhance the efficiency of the simultaneous engineering activities. Intent description is very important from the point of view of quality assurance. Special measures can be taken for the quality in this way. Well-organized application of intent description and the collaborative communication can decrease the throughput time of a project dramatically. Later use of the stored model information become easier because the original intents help in understanding decisions and at possible re-engineering of the product.

Information exchange amongst product designers and production engineers is considered for mechanical parts. Human intent and attaching human intent descriptions to product models are analyzed for computer aided engineering environments. Communication of computer procedures as well as humans are taken into account. An approach and a methodology are proposed by the authors for defining design intent and attaching it to geometric and form feature models of mechanical parts. Description of human experience and application of the model can be involved. Design intent description can be communicated between CAD/CAM systems through conventional and model-based data exchange procedures.

\section{REFERENCES}

Cruinkshank, D. (1996): Two Plus Two Equals Six - Using Collaborative Tools to Make Working Together Work Better, Iris Universe, No. 29, pp. 18-22.

Haasbroek, L. J. (1993): Advanced Human-Computer Interfaces and Intent Support: A Survey and Perspective, in Proceedings of the 1993, IEEE International Conference on Systems, Man and Cybernetics, IEEE Systems, Man and Cybernetics Society, Lille, pp 350-355.

László Horváth and Imre J. Rudas (1994): Human - Computer Interactions at Decision Making and Knowledge Acquisition in Computer Aided Process Planning Systems. Proceedings of the 1994 IEEE International Conference on Systems, Man and Cybernetics, IEEE Systems, Man and Cybernetics Society, San Antonio, pp. 1414-1419

László Horváth and Imre. J. Rudas (1995): Modeling Human Computer Interactions in Collaborative Design and Planning. Proceeding of the 1995 IEEE International Conference on Systems, Man and Cybernetics. Vancouver, Canada, Volume 2, pp. 1899-1903. 
László Horváth and Imre J. Rudas (1997): Attaching Knowledge to Product Model for Representation of Human Intent, Proceedings of the 1997 IEEE International Conference on Systems, Man and Cybernetics, Computational Cybernetics and Simulation, Volume 2, Orlando, Florida, USA, 1997, pp. 1580-1585.

László Horváth and Imre J. Rudas (1996): Generation of Petri Net Representation of Entities for Manufacturing Process Model Using Knowledge Based Methodology, Proceedings of the International Conference on Information Systems Analysis and Synthesis, Orlando, USA, pp. 678-684

Schild, P. J. and Klemm, W. and Walz and G. J., Ruess, H. J. (1995): Open data Exchange with HP PE/Solid Designer, Hewlett-Packard Journal, October 1995, pp. $35-50$

\section{BIOGRAPHY}

László Horváth received the MSc degree in Production Engineering from the Technical University of Budapest in 1971, received the Dr. Techn. degree in computer aided process planning systems from the Technical University of Budapest in 1984 and received the $\mathrm{Ph} . \mathrm{D}$. degree in knowledge based process planning systems from the Hungarian Academy of Sciences in 1992. He is active as professor and deputy director at the Bánki Donát Polytechnic, Budapest, Hungary where currently teaches courses on $\mathrm{CAD} / \mathrm{CAM}$ systems engineering, informatics and knowledge engineering. $\mathrm{He}$ is a member of the New York Academy of Sciences, Senior Member of IEEE Industrial Electronics Society, IEEE Systems, Man and Cybernetics Society and IEEE HumanComputer Interaction Technical Committee. His research interests include modeling of manufacturing processes, application of artificial intelligence in manufacturing process planning, integrating design and planning systems, concurrent and collaborative engineering, product modeling and human-computer interaction.

Imre J. Rudas graduated from Bánki Donát Polytechnic, Budapest in 1971 and received the Master Degree in Mathematics from the Eoetvoes Loránd University, Budapest while the $\mathrm{Ph} . \mathrm{D}$. in Robotics from the Hungarian Academy of Sciences. He is active as professor and Head of Department: Information Technology at Bánki Donát Polytechnic, Budapest. He is an active member of the New York Academy of Sciences, Senior Member of IEEE, and registered expert of the United Nations Industrial Development Organization. He is also a member of the editorial board of Engineering Application of Artificial Intelligence and Control Engineering Practice, member of various national and international scientific committees. His present areas of research activity are: Robot Control, Soft Computing, Computed Aided Process Planning, Fuzzy Control and Fuzzy Sets. He has published more than 150 papers in various journals and international conference proceedings. 